\title{
Modernizacja gniazda produkcyjnego zgodnie z koncepcją Industry 4.0 na przykładzie stanowiska do realizacji procesu wykrawania
}

\author{
Modernization of the work centre \\ in accordance to the Industry 4.0 concept on the example \\ of position for the execution of blanking process
}

\section{Streszczenie}

Koncepcja czwartej rewolucji przemysłowej sprowadza się do zwiększenia wydajności i elastyczności procesów produkcyjnych oraz poprawy jakości życia ludzi. Industry 4.0 dysponuje szeregiem narzędzi technicznych, które między innymi realizują funkcje komunikacji za pośrednictwem sieci Internet elementami składowymi maszyny. Do realizacji pilotażowej modernizacji stanowiska produkcyjnego wykorzystano prasę mimośrodową Instytutu Technik Wytwarzania Politechniki Warszawskiej. Układ napędowy i sterownia zmodernizowano, zakładając wymianę kluczowych danych diagnostycznych z systemem sterowania nadrzędnego. Kolejno uruchomiono systemu akwizycji danych procesowych oparty o urządzenia Kistler maXYmos TL. Całość dopełnia system SCADA wraz z aplikacją administracyjną, które za pośrednictwem odpowiedniego aparatu matematycznego, dążą do realizacji koncepcji predyktywnego utrzymania ruchu i określenia zużycia narzędzia.

Słowa kluczowe: Systemy Cyberfizyczne; Industry 4.0; wykrawanie; monitorowanie procesu

\begin{abstract}
The concept of the Industry 4.0 revolution is related to increasing efficiency, elasticity of production and improving the quality of life. Industry 4.0 has several technical tools that, implements communication between components of machine via the Internet. The mechanical press of the Institute of Manufacturing Technologies at Warsaw University of Technology was used to implement the pilot modernization to Industry 4.0 standard. The control and drive system were upgraded assuming exchange of key diagnostic data with the master control system. The process data acquisition system based on Kistler maXYmos $T L$ was launched. The whole is complemented by SCADA system and administrative application, which using appropriate mathematical calculations realize the concept of predictive maintenance and calculates the tool wear.
\end{abstract}

Keywords: Cyber Physical Systems; Industry 4.0; blanking; process monitoring

\section{Wstęp}

W roku 2011 zaprezentowano nową koncepcję polityki rozwoju gospodarki opartej na nowych technologiach [1]. Data ta jest uznawana za początek 4 rewolucji technologicznej opartej na koncepcjach obejmujących: systemy cyberfizyczne (CPS), Internet przedmiotów (IOT) i Internet usług (IoS) [2]. Zakłada się, że wszystkie te systemy mogą w sposób ciągły komunikować się przez Internet, dzięki czemu możliwa stanie się interakcja między ludźmi (C2C), między ludźmi a maszynami (C2M) i między maszynami (M2M) [3]. Wszystkie te elementy przyczynią się do powstania systemów zarządzania wiedzą 4.0 (KM 4.0) [4]. Zakłada się, że z wymienionych elementów dominującym będzie komunikacja pomiędzy maszynami. W tej sferze będą odbywały się największe przepływy danych. Informacje uzyskiwane z gniazd produkcyjnych spływać będą do centrów przetwarzania danych, gdzie nastąpi autonomiczne wnioskowanie i ocena stanu procesu. W związku z tym wytworzą się nowe schematy organizacyjne przedsiębiorstw produkcyjnych, nowe powiązania pomiędzy komórkami organizacyjnymi i nowe ścieżki przepływu informacji. Na podstawie pracy Bin Cao i in. [5] opisującej koncepcję nowoczesnego zakładu przetwarzającego aluminium można przedstawić ogólną architekturę w standardzie Industry 4.0 dla typowego przedsiębiorstwa produkcyjnego. Ogólny schemat zaprezentowano na rysunku 1.

Dr hab. inż. Piotr Czyżewski, inż. Michał Ernt - Politechnika Warszawska.

Autor korespondencyjny/Corresponding author. p.czyzewski@wip.pw.edu.pl 


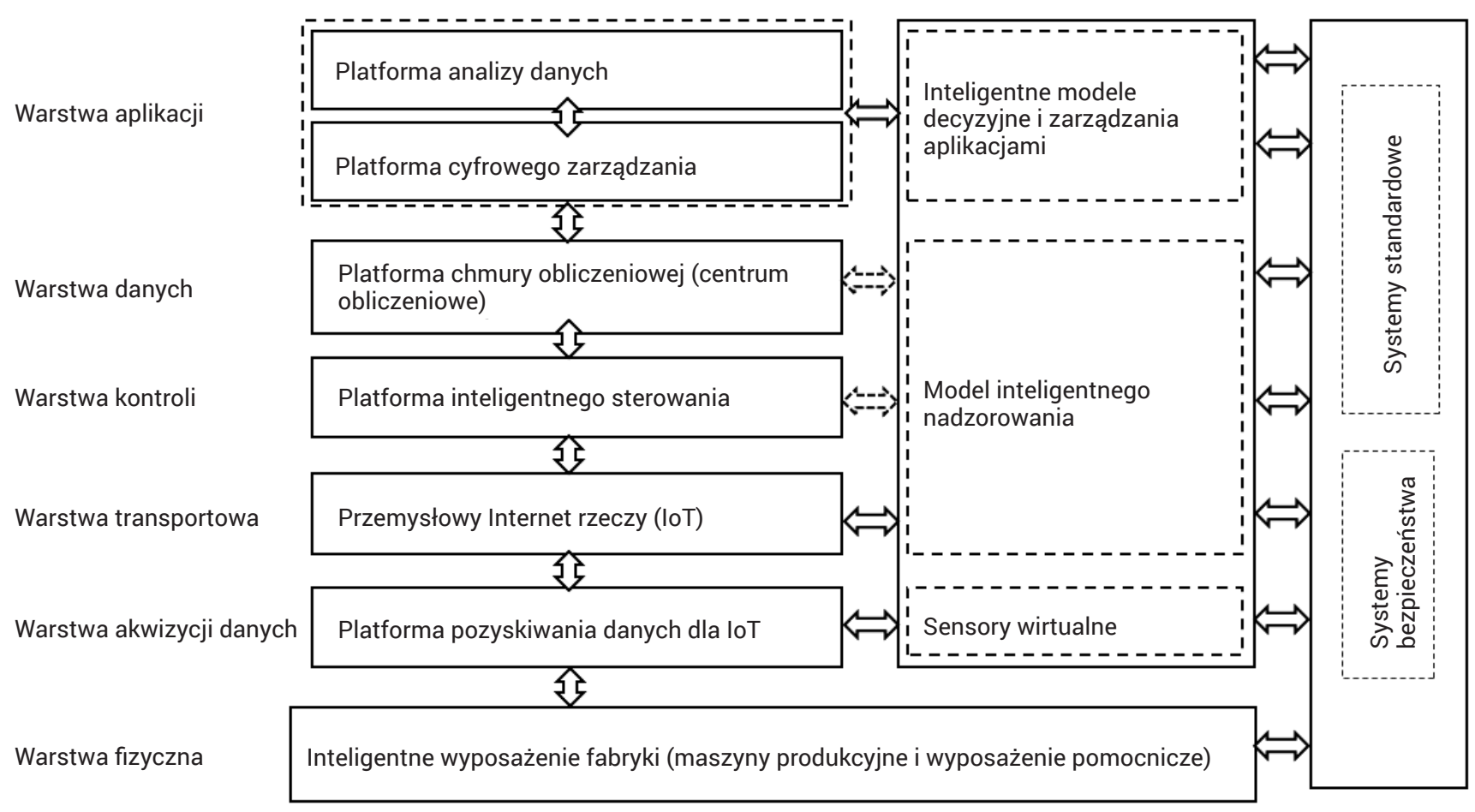

Rys. 1. Schemat infrastruktury fabryki wg koncepcji Industry 4.0

Fig. 1. Diagram of factory infrastructure according to Industry 4.0 concept

Jak widać na przedstawionym rysunku, fizyczna infrastruktura zakładu obudowana jest skomplikowaną infrastrukturą informatyczną. Przepływ informacji jest wielokierunkowy. Dane płyną zarówno w kierunku pionowym, jak i poziomym. Cały model przepływu i przetwarzania informacji podzielony jest na warstwy. Każda z warstw jest autonomiczna, czyli zmiany wprowadzone $w$ dowolnej warstwie nie powinny wymuszać zmian w warstwach sąsiadujących.

W poniższej pracy przedstawiono próbę modyfikacji gniazda produkcyjnego tak, aby spełniało warunki określone koncepcją systemu cyberfizycznego (CPS ang. Cyber Physical System). Do modyfikacji wybrano stanowisko prasy mimośrodowej PMS-16C. Podstawowymi zadaniami były: modernizacja układu napędu i sterowania, implementacja systemu akwizycji danych i budowa systemu pozwalającego na integrację układu z systemem przetwarzania i analizy danych. Dodatkowo opracowano moduł, który jest niejako interfejsem pomiędzy zbudowanym układem CPS a systemem analizy danych i systemem decyzyjnym. W odniesieniu do rysunku 1 można stwierdzić, że modernizacja dotyczyła: warstwy fizycznej, warstwy akwizycji danych i warstwy transportowej. Dzięki temu powstało gniazdo produkcyjne, które jest jednostką łatwo dołączalną do dowolnego systemu produkcyjnego funkcjonującego wg koncepcji Industry 4.0.

\section{Modernizacja maszyny technologicznej do standardu Industry $\mathbf{4 . 0}$}

Do modernizacji wybrano stanowisko badawcze Zakładu Obróbki Plastycznej i Odlewnictwa Instytutu Technik Wytwarzania Politechniki Warszawskiej wyposażone w prasę mimośrodową PMS16C wyprodukowaną w roku 1977 o nacisku nominalnym 16 t, układ podawania blachy składający się z bębna rozwijającego i prostowarki oraz podajnika pneumatycznego. Podajnik zapewnia precyzyjne podawanie taśmy do przestrzeni roboczej w cyklu pracy automatycznej. Prasa dzięki wykonanym pracom została zmodernizowana zgodnie z koncepcją Industry 4.0. Pierwszy etap prac zakładał modernizację układu sterowania prasy na taki, który jest w stanie zbierać informację o parametrach silnika napędzającego prasę, takich jak: napięcie, prąd i aktualna prędkość obrotowa oraz udostępniać je wykorzystując jedną z powszechnie używanych sieci przemysłowych do układu sterowania nadrzędnego SCADA. W tym celu stanowisko wyposażono $\mathrm{w}$ falownik pozwalający na płynną zmianę szybkobieżności prasy w zakresie od 50 do 200 cykli/min. Jednocześnie informacje o aktualnych parametrach pracy mogą być przekazywane do sterownika prasy, Dodatkowo wybrano taki sterownik PLC, który jest w stanie przesyłać do wyższej warstwy systemu podstawowe dane diagnostyczne takie jak: temperatura wewnątrz obudowy, status pamięci, stan wejść/wyjść, prawidłowość działania wyjść.

Kolejnym etapem był montaż i uruchomienie systemu akwizycji danych procesowych. Do tego celu wybrano rozwiązanie firmy Kistler. maXYmos TL (Top Level). MaXYmos TL to urządzenie rejestrujące, analizujące i oceniające parametry procesu takie jak siła, emisja akustyczna i inne, które przebiegają liniowo w funkcji drogi lub czasu. Widok interfejsu użytkownika z ekranem diagnostycznym przedstawia rysunek 2 . Jest to urządzenie przeznaczone do kontroli

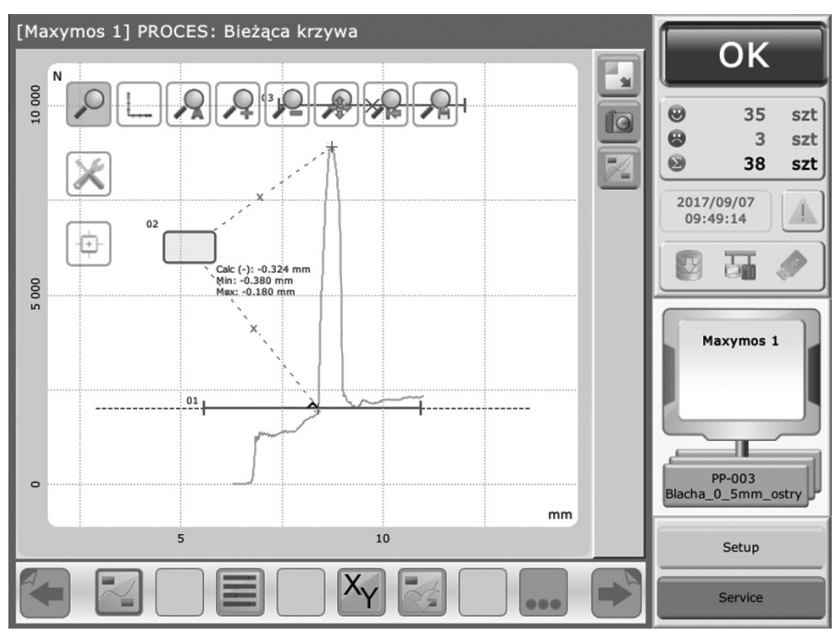

Rys. 2. Przykładowy przebieg sygnałów procesowych w systemie maXYmos TL

Fig. 2. An example of signal graph registered by maXYmos TL 
prawidłowości procesu produkcyjnego. Ma ono jedynie możliwość diagnostyki procesu pod kątem jego prawidłowego przebiegu, czyli otrzymujemy informację zero-jedynkową: dobrze-źle. Niestety nie ma wbudowanych narzędzi predykcyjnych pozwalających na ocenę stanu w szerszej perspektywie czasowej. Istotną funkcjonalnością, z punktu widzenia prowadzonych prac modernizacyjnych, jest nie tylko możliwość oceny przebiegów jako „OK" lub „NOK”, ale również archiwizacji danych pomiarowych i przesyłanie ich do zewnętrznych systemów, gdzie mogą zostać poddane dokładniejszej analizie. Na stanowisku badawczym zamontowano dwa urządzenia Kistler maXYmos TL. Jedno z nich służy do pomiaru, rejestracji i analizy przebiegu siły względem przemieszczenia, drugie natomiast do rejestracji sygnału RMS (ang. Root Mean Square - średnia kwadratowa) emisji akustycznej w funkcji drogi. Urządzenia zostały zintegrowane $z$ systemem SCADA. System ten zbiera dane ze sterownika PLC oraz przebiegi siły (rys. 3) i emisji akustycznej rejestrowanej podczas procesu wykrawania. Dane odebrane przez aplikację sterowania nadrzędnego są identyfikowane za pomocą numeru ID procesu. Dzięki temu rozwiązaniu istnieje miejsce, w którym wszelkie dane procesowe mogą być analizowane i przeglądane oraz poddawane dalszej analizie celem realizacji poglądu predyktywnego utrzymania ruchu. Schemat połączeń układu rejestrującego dane procesowe przedstawiono na rysunku 3.

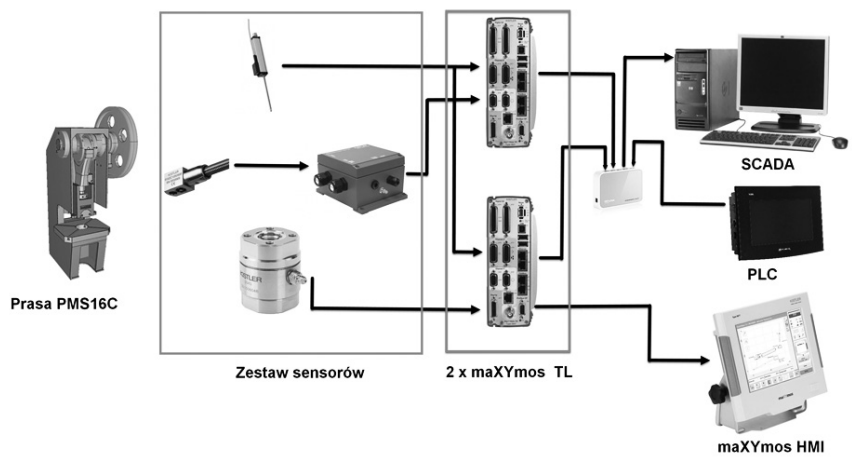

Rys. 3. Schemat połączeń układu rejestrującego dane procesowe Fig. 3. Diagram of data acquisition system connections

\section{System analizy danych procesowych}

Następnym etapem modernizacji stanowiska było opracowanie algorytmu analizującego dane pomiarowe celem realizacji koncepcji predyktywnego utrzymania ruchu. W tym celu na prasie zamontowano przyrząd do wykrawania. Materiałem wykrawanym była blacha elektrotechniczna. Materiał ten został wybrany ze względu na to, że tego typu blacha nie ma, określonych normą, stałych własności mechanicznych [6]. Wobec tego wykorzystując blachy od różnych dostawców, wprowadzano dodatkowe zakłócenie w danych procesowych. System SCADA otrzymując dane pomiarowe z urządzeń maXYmos TL i sterownika PLC przeprowadza szereg działań celem uzyskania informacji o procentowym zużyciu stempla wykrojnika. Sygnały rejestrowane podczas pomiaru wielkości fizycznych charakterystycznych dla procesów wytwarzania nigdy nie oddają idealnie rzeczywistości. Mogą one być zakłócane przez wiele czynników, jak chociażby częstotliwość pomiaru czy bezwładność czujnika. W omawianym przypadku, na sygnał będący pomiarem siły wykrawania nałożony został filtr wygładzający $4253 \mathrm{H}$. Jest to pięcioetapowa operacja matematyczna mająca na celu wyeliminowanie oscylacji o krótkim czasie, co powoduje wygładzenie wykresu. Na tej podstawie w czasie rzeczywistym obliczane są charakterystyczne wielkości procesu i jednocześnie porównywane z zaimplementowanym wcześniej wzorcem, ustalonym w trakcie testowania systemu. System raportuje w przypadku, kiedy analizowane dane znacząco odstają w swym charakterze od modelu dla narzędzi nowych lub zbliżają się do modelu narzędzi zużytych. To działanie informuje nadzorcę o konieczności przerwania procesu i wymiany stempla przed krytycznym uszkodzeniem stempla i uzyskaniem wadliwych wyrobów [7]. Tego typu rozwiązanie pozwala na planowanie przestojów i optymalne pod względem produkcji realizowanie koniecznych napraw i konserwacji co znacząco zwiększa produktywność. Jednocześnie tak przetworzone informacje mogą zostać wykorzystane jako weryfikatory wyników uzyskiwanych w środowisku wirtualnym [8].

\section{System administracji danymi z gniazd technologicznych}

Ostatni etap modernizacji zakładał uruchomienie aplikacji nadrzędnej, która w sposób wygodny zapewni dostęp do danych diagnostycznych. Aplikacja miała spełniać następujące założenia:

1. Należy zapewnić dostęp do aplikacji z dowolnego komputera bez potrzeby instalacji dodatkowych programów - aplikacja webowa.

2. Należy zapewnić dostęp do aplikacji z urządzeń wyposażonych w interfejs bezprzewodowy i mobilnych np. tablet, telefon komórkowy.

3. Informacje prezentowane przez aplikację mają być przedstawione w sposób jednoznaczny i czytelny, umożliwiający łatwą i szybką diagnostykę stanowiska.

4. Dopuszczalne jest jedynie sterowanie parametrami, które nie wpłyną na bezpieczeństwo obsługi.

5. System ma umożliwiać dostęp do dokumentacji, kodów źródłowych, schematów stanowiska celem szybkiej naprawy ewentualnych usterek [2].

6. System musi przedstawiać informacje związane $z$ predyktywnym utrzymaniem ruchu.

7. System ma być elastyczny tak, aby w łatwy sposób można było dołączać dane z kolejnych gniazd produkcyjnych. Realizację aplikacji oparto o mikrokomputer Raspberry Pi 3 z zainstalowanym środowiskiem Codesys V3 opracowanym przez 3S-Smart Software Solutions GmbH. Tego typu podejście umożliwiło nawiązanie komunikacji z każdym z urządzeń stanowiska badawczego oraz pozwoliło na realizację powyższych założeń. Dodatkowo umożliwia rozbudowę aplikacji o kolejne stanowiska, które mają być poddane monitorowaniu dzięki szerokiemu wachlarzowi możliwości komunikacyjnych [9].

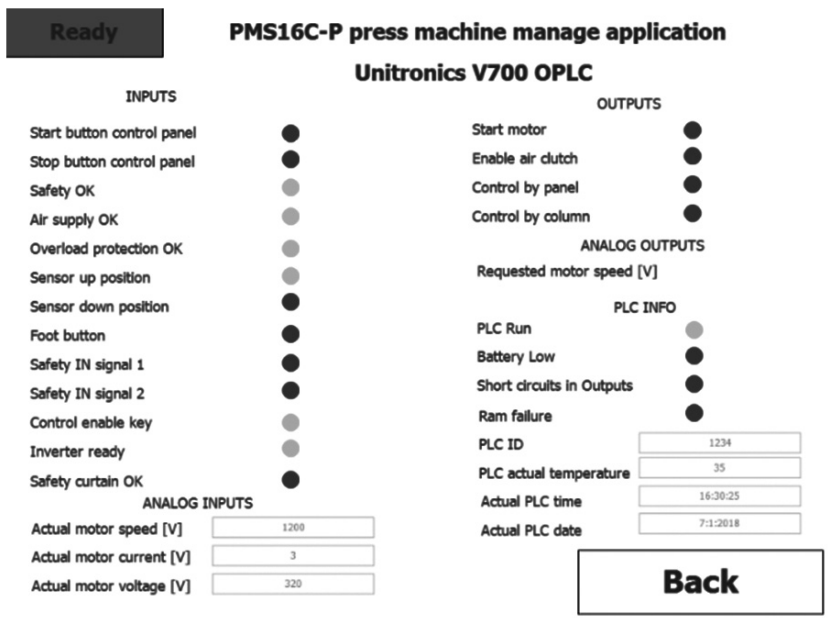

Rys. 4. Przykładowy ekran aplikacji administracyjnej

Fig. 4. An example of screen of administrative application 


\section{Podsumowanie}

W wyniku podjętych prac zmodernizowano istniejące stanowisko badawcze zgodnie z koncepcją Industry 4.0. Powstałe modelowe gniazdo technologiczne stanowi przykład systemu cyberfizycznego (rys. 5). Jest to system otwarty, do którego można dołączać kolejne gniazda technologiczne. Jednocześnie zrealizowano zadanie systemu cybernetycznego do oceny

\section{Układy sterowania}

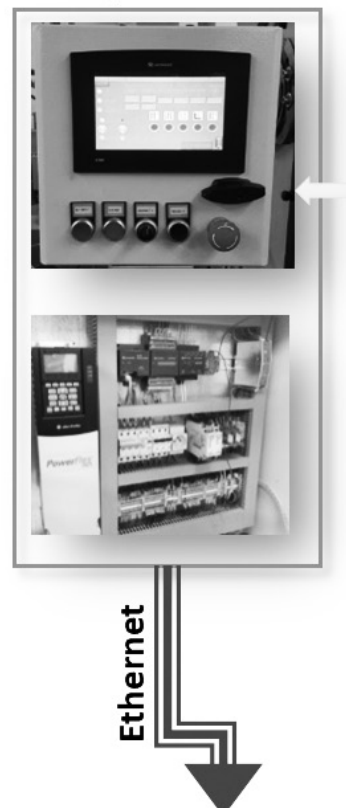

Gniazdo produkcyjne
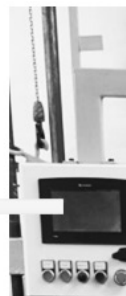

prod
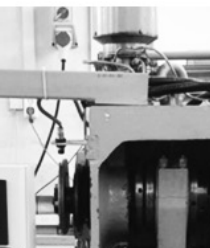
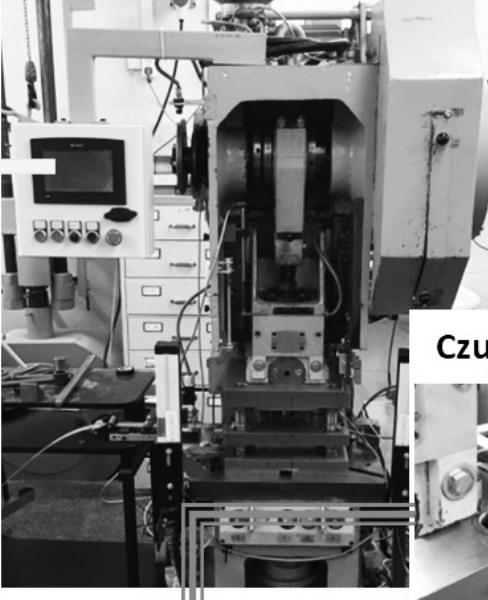

Parametry maszyny

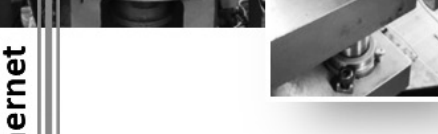

Czujniki

System monitorowania

procesu

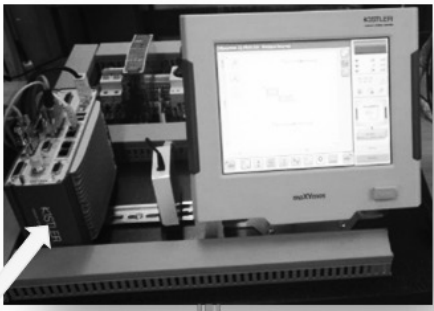

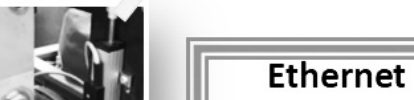

SCADA

System decyzyjny

Rys. 5. Schemat działania systemu cyberfizycznego (CPS) powstałego po modernizacji gniazda technologicznego na bazie prasy PMS-16C Fig. 5. Diagram of the cyberphysical system (CPS) created according to the modernization of PMS-16C

stanu zużycia narzędzi na podstawie sygnałów z systemu akwizycji danych.

Podstawowe cechy:

- system bazujący na elementach rejestrujących i monitorujących kluczowe parametry procesu technologicznego (DAQ-system);

- system sterowania umożliwiający zdalne sterowanie nastawami urządzeń gniazda technologicznego (IoT);

- implementacja systemu SCADA do analizy gromadzonych danych produkcyjnych i predykcji stanu narzędzia.

Praca naukowa finansowana ze środków Narodowego Centrum Nauki jako projekt badawczy nr N N508 628140

\section{Literatura}

[1] Masconi F.: The New European Industrial Policy, Routledge, London, 2015 doi:10.4324/9781315761756.

[2] Lasi H., Fettke P., Feld T., Hoffmann M.: Industry 4.0, Bus. Inf. Syst. Eng. 6, 2014.

[3] Cooper J., James A.: Challenges for Database Management in the Internet of Things, IETE Tech. Rev. 26 (2009) 320. doi:10.4103/0256-4602.55275.

[4] Dominici G., Roblek V., Abbate T., Tani M.: Click and drive: Consumer attitude to product development: Towards future transformations of the driving experience, Bus. Process Manag. J. 22, 2016, pp. 420-434. doi:10.1108/ BPMJ-05-2015-0076.

[5] Cao B., Wang Z., Shi H., Yin Y.: Research and practice on Aluminum Industry 4.0, 2015 Sixth Int. Conf. Intell. Control Inf. Process. 2015, pp. 517-521. doi:10.1109/ICICIP.2015.7388226.
[6] Czyżewski P., Kochański A., Cacko R., Maciołek T.: Badanie wybranych własności blach elektrotechnicznych, Przegląd Elektrotechniczny, 93, 2007, s. 92-96.

[7] Sikorski B.: Projekt i wykonanie modułu analizy deskryptorów procesu technologicznego na przykładzie operacji wykrawania, Politechnika Warszawska, 2018.

[8] Czyżewski P., Kochański A., Moszczyński L.: Modelowanie parametrów procesu wykrawania dla różnych stanów zużycia stempla, Przegląd Mech., 2016, s. 23-26. doi:10.15199/148.2016.5.1.

[9] Ernt M.: Modernizacja wybranego gniazda produkcyjnego do standardu Industry 4.0., Politechnika Warszawska, 2018. 